\title{
Blood and bone marrow donor registry of Istanbul medical faculty activity and experience in past 3 years
}

\section{A cross-sectional documentation of TRIS activity: the first blood and marrow registry in Turkey}

\author{
Fatma Savran Oguz • Ayse Erol • Cigdem Kekik Cinar • Demet Kivanc • \\ Mediha Suleymanoglu $\cdot$ Yeliz Ogret $\cdot$ Hayriye Senturk Ciftci $\cdot$ Sevgi Kalayoglu Besisik
}

Received: 8 June 2021 / Accepted: 22 September 2021/Published online: 16 October 2021

(C) The Author(s), under exclusive licence to Springer Nature B.V. 2021

\begin{abstract}
Allogeneic stem cell transplantation (SCT) offers a potential cure for some hematological malignancies. For those patients without a family donor, unrelated donor (MUD) registries serve for identifying the best donor. In the present study, we aimed to give a cross-sectional report of our registry's activity and experience as the first established national MUD registry in the country. The study is retrospective and covers the period of 2016 to 2019. A total of 1855 donor searches were performed, and 642 were included in the study. All data were electronically obtained from the institutional database system. All SCTs were either $10 / 10$ or 9/10 HLA matched and originated from an international registry. The most
\end{abstract}

F. Savran Oguz $(\bowtie) \cdot$ C. Kekik Cinar .

D. Kivanc · M. Suleymanoglu · Y. Ogret ·

H. Senturk Ciftci

Istanbul Faculty of Medicine, HLA Laboratory, Istanbul

University, Istanbul, Turkey

e-mail: oguzsf@gmail.com; oguzsf@istanbul.edu.tr

C. Kekik Cinar

e-mail: citcim@gmail.com

D. Kivanc

e-mail: demetkivanc@hotmail.com

M. Suleymanoglu

e-mail: medihas@gmail.com

Y. Ogret

e-mail: yelizdogret@gmail.com

H. Senturk Ciftci

e-mail: hayriyesenturk@gmail.com preferred stem cell source was peripheral blood (70.2\%). A quarter of transplants were performed using bone marrow, and cord blood was used with a rate of $1.4 \%$. The pandemic-related problems were similar for the other two national registries. During the pandemic, 71 of 432 patients who were searched for donors underwent stem cell transplant(SCT). The low number was related mostly with postponing of SCTs and/also difficulties in continuing of volunteering and in achievement of stem cells from international registry. During the Covid19 pandemic, the SCT activity of centers decreased according to the national, and international guidelines. The study revealed an organized, and multidirectional capacity of the

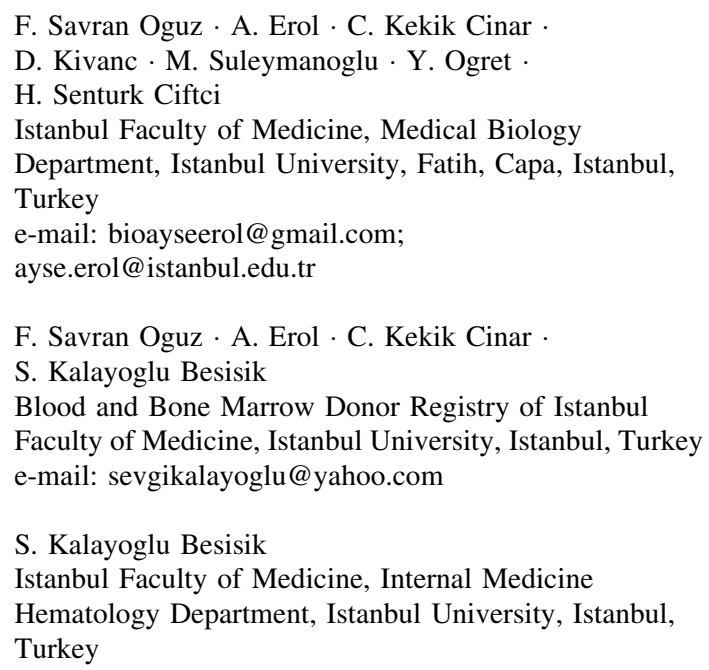


registry and also the adaptation to unpredicted conditions such as pandemic. On the other hand, there is a need for more effective strategies for donor recruitment and retention programme.

Keywords Blood and bone barrow bank - Donor registry $\cdot$ Unrelated hematopoietic stem cell transplantation $\cdot$ HLA

\section{Introduction}

Allogeneic stem cell transplantation (ASCT) is a therapeutic modality for various diseases, particularly for hematological malignancies (Koopmans et al. 2003; Mahmoud 2020). It is well established that the success of ASCT correlates with Human Leukocyte Antigen (HLA) matching between the stem cell donor, and patient. For patients with no available donor within the family, the volunteer donor registries serve to identify a matched unrelated donor (MUD) or a cord blood unit (Juric et al. 2016; Yurdakul and Beksaç 2019).

Turkey has a high rate of consanguineous marriage. Therefore, it is expected that finding a HLA matched family member donor will be much more likely. Indeed, the rate of HLA matched related donor transplantation is approximately $30 \%$ which is similar to the worldwide experience (Koopmans et al. 2003; Mahmoud 2020; Yurdakul and Beksaç 2019; Fumimaro Takaku1 on behalf of JMDP 2018; Kollman et al. 2001; Stanworth et al. 2001; Gratwohl et al. 1996).

Currently, over 38 million volunteer donors are registered within 75 blood and bone marrow registries in 53 countries, and there are 53 cord blood registries in 36 countries. The World Marrow Donor Association (WMDA) organization promotes global collaboration among these registries, and transplant centers. Most registries are in Europe (particularly in West, and North Europe) and North America. In Eastern Europe, the number of the registries and registered donors are yet limited (Fumimaro Takaku1 on behalf of JMDP 2018; Kollman et al. 2001; Stanworth et al. 2001; Gratwohl et al. 1996; WMDA 2020; Zlatev et al. 2008; Cleaver et al. 1997). As being a bridge between Europe and Asia, Turkey has three public blood and bone marrow registries. The Turkish blood and bone Marrow donor registry of Istanbul Faculty of Medicine (Shortcode:TRIS- Turkish Registry of Istanbul) is the first registry which was established in 1999, when the number of transplant centers was increasing in the country. The main work of TRIS was searching for donors to find out a MUD from international registries. In 2008, TRIS was restructured with updating of registered donors, planning new donor recruitment programs and accelarating the search duration. TRIS is now a member of WMDA with 26.724 WMDA registered donors and works with Istanbul Medical Faculty HLA typing laboratory which is accredited by the European Federation for Immunogenetics (EFI). The second registry was established at Ankara University with the name of TRAN. TRAN has 15.269 WMDA registered donors. Both TRIS and TRAN function as the university affiliated registries. A recently organized registry is within the body of the Ministry of Health with the name of Turkish Stem Cell Coordination Centre (TURKOK) and has 600.000 WMDA registered donors. Turkey has only one cord blood bank dedicated to allogeneic transplantation at Ankara University and has 1537 cord bloods ready to use. All these three banks are public banks and work in coordination with each other. According to the rules of the Ministry of Health, the search for a MUD should be started first by the Turkish blood and bone marrow banks. If no 10/10 or 9/10 MUD matched donor is detected in these three banks of TRIS, TRAN and TURKKOK, search for foreign registered donors is allowed.

With this study, we aimed to present the processes of screening and transplantation organization, potential troubles in these processes and a cross-sectional report of TRIS activity which may pave the way for designing a cooperated study in the future.

\section{Statistics}

Statistical analyses were performed using the Statistical Package for the Social Sciences(SPSS) software version 21. Descriptive statistics were generated for demographic data. Frequencies were given in percentages. Statistical comparisons were made using the Chi-square test for categorical data. A $p$ value of $<$ 0.05 was considered statistically significant.

\section{Material and method}

The study is retrospective and covers a period of years between 2016, and 2019. The data during the 
pandemic were separately assessed. The search data for MUD were collected when the search was completed with SCT. All data were obtained electronically from institutional database system.

The study was approved by Istanbul Faculty of Medicine local ethics committee (no:2021/231).

\section{Results}

During these years excluding the pandemic, a total of 1855 donor searches were performed and 642 were accomplished with SCT. All donors were either 10/10 or 9/10 HLA matched and originated from international registries.

A male dominance was slightly remarkable among the patients. The gender distribution among the donors was approximately equal. The demographic characteristics are shown in Table 1. More than half of the transplants were gender mismatched with a female preponderance in the donors (Table 2). The ABO blood group distribution data were achievable in 418 patients. Most patients had blood group A (42\%). The second common blood group was group $\mathrm{O}(30.8 \%)$. The frequencies of Group B, and Group AB were 19.6 and $7 \%$, respectively. $\mathrm{ABO}$ incompatibility was detected in $67 \%$ of the transplants with a minor and major incompatibility rate of 29 and $23 \%$, respectively (Fig. 1).

The HLA 10/10 matched transplant ratio was found as $47.7 \%$. The most common antigen/allele mismatch type was within the HLA-A loci being $41 \%$ and this was followed by HLA B, C, DR, and DQ (Fig. 2). The HLA mismatch ratio was not statistically significant between the adult, and pediatric patients.

The most commonly used stem cell source was peripheral blood with a rate of $70.2 \%$. Cord blood was used with a rate of $1.4 \%$. Bone marrow was preferred by approximately $25 \%$ of the patients. Most of them were paediatric patients. For one patient, the transplant center's request was peripheral blood stem cell collection in addition to bone marrow due to poor bone marrow stem cell yield.

Donor leukocyte infusions (DLIs) were provided for 21 patients in these years.

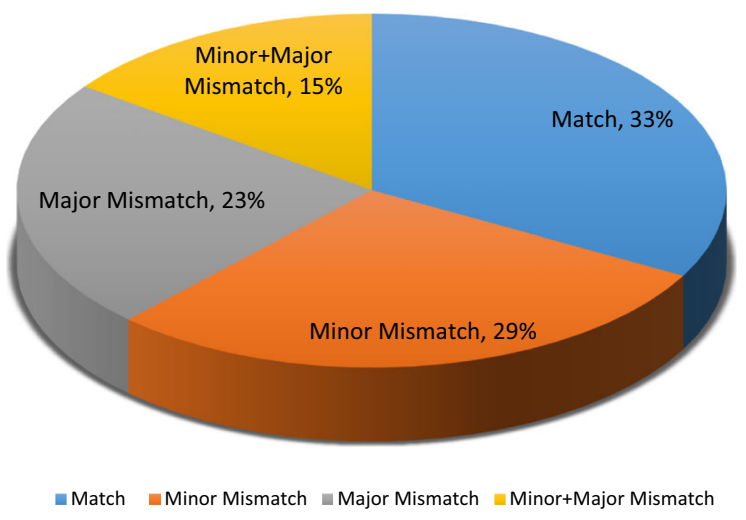

Fig. 1 The ABO compatibility distribution

Table 1 Demographic data of the patients, and donors

\begin{tabular}{|c|c|c|c|c|}
\hline \multicolumn{2}{|c|}{$\begin{array}{l}\text { No. of patients and } \\
\text { donors N: } 642\end{array}$} & \multirow{2}{*}{$\begin{array}{l}\text { Age (year) } \\
42.27(18-74)\end{array}$} & \multirow{2}{*}{$\begin{array}{l}\text { Gender (F/M) } \\
217 / 144\end{array}$} & \multirow{2}{*}{$\begin{array}{l}\text { Disease } \mathrm{N} \\
\text { AML: } 145 \text { ALL: } 130 \text { CML: } 16 \text { SAA: } 49 \text { HL and NHL: } 54 \text { Others:246 }\end{array}$} \\
\hline Patient & Adult & & & \\
\hline Patient & Pediatric & $7.27(1-18)$ & $160 / 121$ & \\
\hline Donor & & $31.9 \pm 9.6(18-66)$ & $304 / 333$ & \\
\hline
\end{tabular}

Table 2 Characteristics of transplants

\begin{tabular}{|c|c|c|c|c|c|}
\hline & & Stem cell sources & GenderMM (Donor) & Patient) & ABO MM \\
\hline \multirow[t]{2}{*}{$\begin{array}{l}\text { Total Patient } \\
\text { (n:642) }\end{array}$} & Adult & $\begin{array}{l}\text { PBSC: } 313 \text { BM: } 31 \text { Cord:0 } \\
\text { DLI: } 15\end{array}$ & \multirow[t]{2}{*}{$\begin{array}{l}\text { F/M 25.9\% (n:123/ } \\
\quad 637)\end{array}$} & \multirow[t]{2}{*}{$\begin{array}{l}\mathrm{M} / \mathrm{F} 19.3 \% \\
\quad(\mathrm{n}: 165 / 637\end{array}$} & \multirow[t]{2}{*}{$\begin{array}{l}\text { Matched: } 33 \% \\
\text { Mismatched: } 67 \%\end{array}$} \\
\hline & Pediatric & $\begin{array}{l}\text { PBSC: } 137 \text { BM: } 130 \text { Cord: } 8 \\
\text { DLI: } 6\end{array}$ & & & \\
\hline
\end{tabular}


Among MUD providing countries, Germany was the main source and this was followed by Poland and The Unites States (Fig. 3).

The most common indication for transplantion was leukemia with a rate of $47.7 \%$. The second most common indication was bone marrow failure disorders such as myelodysplastic syndrome (MDS) and severe aplastic anemia (SAA) with a ratio of 9.8 and $9.1 \%$, respectively. Other indications were thalassemia (8.6\%) and lymphoma (6.3\%).

In March 2020, when the pandemic was declared, the regional transplant centers started to postpone SCT in parallel with national and international recommendations. Based on this, 71 of 432 patients who were searched for donors underwent SCT. Most (74\%) of the donors were provided from Germany's blood and

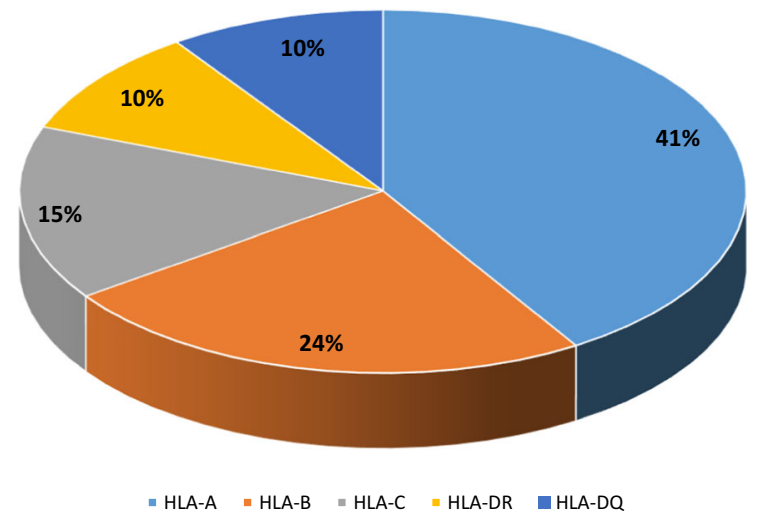

Fig. 2 Antigen/allele HLA mismatch distribution bone marrow banks (DKMS and ZKRD) for 44 adult, and 27 pediatric patients. Again, peripheral blood was the most commonly preferred stem cell source (n:62). The remaining stem cell sources were all bone marrows. Cord blood was not used. Only one DLI was transferred. The donors were 10/10 HLA matched in 41 cases, and 9/10 HLA matched in 30 cases. For the remaining 33 completed searches, SCTs were either cancelled (n:19) or postponed (n:14).

During the study period, only 2 searches were performed to find out HLA matched platelet donors.

\section{Discussion}

Turkey is one of the countries which has a high rate of consanguineous marriages. Owing to that, extended family searches may facilitate donor availability. Interestingly, the present HLA identical sibling ratio $(30 \%)$ is similar to that reported from Europe and/or USA which may be related with a high level of ethnic mixture of the population in this country resulting in rare HLA types (Gratwohl et al. 1996). Regional blood, and bone marrow registries are therefore crucial. Based on this conjuncture, TRIS was established as the first registry in the country. At the beginning, the activitity of TRIS was mainly based on donor search and proceeding to SCT in collobaration with transplant centers in Turkey. After restructuring in 2008, the TRIS activity showed a significant and detailed revival including new donor recruitment
Fig. 3 Countries distribution from which stem cells were obtained

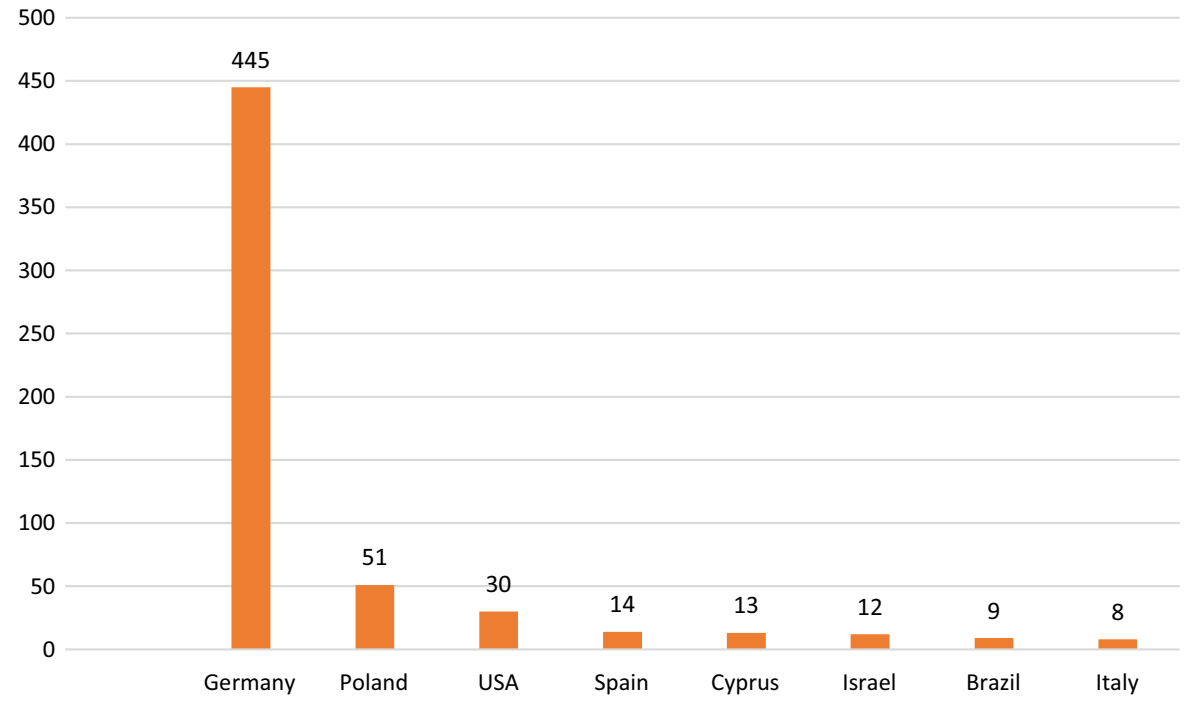


programs, collaborated work with harvesting centers, finding solutions for accelarating donor search duration and providing consultation service for donor preference. Reflection of these changes was manifested by 6966 donor searches which contributed to 1390 ASCTs and 32 DLIs. This restructuring was also an adaptation to the increase in the number of transplant centers and center experience, and also to financial support of health insurance. On the other hand, TRIS is a government-dependent institution which may contribute to financial compromise.

During the pandemic, management was shifted to standart treatment and postponing of SCT in possible cases similar to all transplant centers worldwide. There were also difficulties in continuing of volunteering among donors and achievement of stem cells from international registries (https://share.wmda.info/display/LP/

Coronavirus+Impact+on+Registry+Operationspreview $=/ 344866402 /$

344867270/WBMT_COVID-19-2.pdf\#Coronavirus-

ImpactonRegistryOperations

WorldwideNetworkForBloodMarrow

Transplantation(WBMT) Accessed 4 March 2020). However, multiple connecting flights had to be used due to the pandemic. At customs entry, stem cell transfer to Turkey was generally by foreign courier companies arranged by TRIS and the stem cell product transfer to transplant centers was safely performed in the shortest time as possible. However, limitations of flights in most countries due to the pandemic caused an average delay of $12 \mathrm{~h}$ for delivery of products to transplant centers. Some transplant centers committed to haploidentical SCT in appropriate cases. Others adaptation was early ordering of stem cells and storage them as cryopreserved with at least a 14-day quarantine. Collection of stem cells were from asymptomatic and PCR negative donors. All donors were screened for SARS-CoV-2 by PCR with an interval of one week. Donors suspected of the symptoms suggesting COVID-19 were used when transplant physicians considered the benefit-risk ratio is in favor of benefit, with signed informed consent from patients and health authority approval.

Our study showed that the main MUD source was Germany. The large number of registered donors in this country may be one important factor for this result. On the other hand, some of the Turkish migrant workers in Germany had German citizenship and registered as volunteer donors which might be another factor (Schmidt et al. 2009).
The homogenous HLA matching status between donor-patient pairs as either $10 / 10$ or $9 / 10$ HLA matched may point to the irrepressible wish of transplant centers to decrease the incidence of graft versus host disease. On the other hand, ABO incompatibility between patient and donor has become an easily managable SCT characteristic due to sufficient sophistication of blood banks and apheresis technology in the country. Therefore, ABO incompatibility is no more an exclusion criterion for refusing donors. (Conferl et al. 2016; Kimura et al. 2008). Predominance of peripheral blood usage is partially related with donors' preference and partially related with transplant centers' preference (Gratwohl 2012).

In general, the study revealed an organised and multidirectional capacity of registry and easy adaptation to unpredicted conditions such as pandemic. On the other hand, the study showed that more effective donor acquisition programs are needed with comprehensive social work to keep donors with the registry (WMDA 2020). In addition, we realized that cooperation between transplant centers and blood and bone marrow centers weakened after transplantation. We suggest that the data we present in this report may be effective in solving problems.

Acknowledgements We would like to thank to all volunteer donors and the bone marrow transplant units for performing the transplants of the cases indicated in our study.

Data availability The datasets generated during and/or analysed during the current study are available from the corresponding author (Fatma Savran Oğuz) on reasonable request.

\section{References}

Cleaver SA, Warren P, Kern M, Hurley CK, Raffoux C, Keller J, Kiesel U, Koza V, Marry E, Mitterschiffthaler A, Nakamura M, Okah CT, Persson U, Radde-Stepaniak T, Koopmans EMJW, Ranson L, Raymond J, do Rosariosancho M, Varla-Leftherioti M, Wiegand T, Winterhager JM, Woodfield DG (1997) Donor work-up and transport of bone marrow-recommendations and requirements for a standardized practice throughout the world from the donor registries and quality assurance working groups of the world marrow donor association. (WMDA). Bone Marrow Transplant 20:621-629

Gratwohl A (2012) The EBMT risk score. Bone Marrow Transplant 47(6):749-756

Gratwohl A, Hermans J, Baldomero H, Tichelli A, Goldman JM, Gahrton G (1996) Indications for haemopoietic precursor 
cell transplants in Europe. European group for blood and marrow transplantation (EBMT). Br J Haematol 92:35-43

https://share.wmda.info/display/LP/Coronavirus+Impact+on+ Registry+Operations?preview=/344866402/344867270/ WBMT_COVID-19-2.pdf\#Coronavirus-ImpactonRegistry Operations WorldwideNetworkForBlood\&MarrowTransplantation(WBMT) Accessed 4 March 2020

Juric MK et al (2016) Milestones of hematopoietic stem cell transplantation - from first human studies to current developments. Front Immunol 7:470. https://doi.org/10. 3389/fimmu.2016.00470

Kimura F, Sato K, Kobayashi S et al (2008) Japan Marrow Donor ProgramImpact of AB0-blood group incompatibility on the outcome of recipients of bone marrow transplants from unrelated donors in the Japan Marrow Donor Program. Haematologica 93(11):1686-1693

Kollman C, Howe CW, Anasetti C, Antin JH, Davies SM, Filipovich AH, Hegland J, Kamani N, Kernan NA, King R, Ratanatharathorn V, Weisdorf D, Confer DL (2001) Donor characteristics as risk factors in recipients after transplantation of bone marrow from unrelated donors: the effect of donor age. Blood 98:2043-2051

Kollman C, Spellman SR, Zhang MJ, Hassebroek A, Anasetti C, Antin JH, Champlin RE, Confer DL et al (2016) The effect of donor characteristics on survival after unrelated donor transplantation for hematologic malignancy. Blood 127(2):260-267

Koopmans EMJW, Schattenberg A, Joosten I, Preijers F, De Kort WLAM (2003) Analysis of 127 stem cell donations of the regional bone marrow donor bank europdonor Nijmegen. Neth Leuk Lymphoma 44(6):983-987

Mahmoud HK, Fathy GM, Elhaddad A, Fahmy OA, AbdelMooti M, Abdelfattah R, Bokhary M (2020) Hematopoietic stem cell transplantation in Egypt: challenges and opportunities. Mediterr J Hematol Infect Dis 12(1):e2020023

Saito H, Ito M, Kato S, Kodera Y, Okamoto S, Taniguchi S, Takanashi M, Kanamori H, Masaoka T, Takaku F (2018) on behalf of JMDP The Japan Marrow Donor Program, 25 years of experience inachieving 20,000 bone marrow transplantations: organizationstructure, activity, and financial basis. Bone Marrow Transplant 53:609-616

Schmidt AH et al (2009) Criteria for initiation and evaluation of minority donor programs and application to the example of donors of Turkish descent in Germany. Bone Marrow Transplant 44(7):405-412

Stanworth S, Warwick R, Fehily D, Persaud C, Armitage S, Navarrete C, Contreras M (2001) An international survey of unrelated umbilical cord blood banking. Vox Sang 80:236-243

WMDA.https://wmda.info/wp-content/uploads/2020/02/WMDAStandards-2020-copyright-version-Final-table-of-content-. pdf

WMDA (2020) Total number of donors and cord blood units. https://statistics.wmda.info/; [accessed 09.19]

Yurdakul P, Beksaç M (2019) Kordon Kanı Bankacılığı Ve Nakli. Hematolog 236-245

Zlatev A, Ivanova M, Michailova S, Mihaylova A, Naumova E (2008) Bulgarian bone marrow donors registry-past and futuredirections. Cell Tissue Bank 9:347-351

Publisher's Note Springer Nature remains neutral with regard to jurisdictional claims in published maps and institutional affiliations. 